\title{
Core Orientations for 4.0 Technology Application on the Development Strategy of Intelligent Transportation System in Vietnam
}

\author{
Hoang Phuong Nguyen \\ Academy of Politics Region II, Ho Chi Minh City, Vietnam \\ E-mail: nghoangphuong11@gmail.com
}

\begin{abstract}
The Industrial Revolution 4.0 is having a substantial impact on countries in many fields such as industry structure, human resource needs, production management systems. Transportation is a high-community industry, so it will also be strongly affected by this industrial revolution. The achievements of Industry 4.0 can reshape the nation's transportation systems. That poses challenges for transportation managers to change the operating model as well as the transport-related policies. Building and developing intelligent transport systems (ITS) is attracting considerable attention, research, and investment to serve the development of transportation systems in the world as well as in Vietnam. Vietnam is gradually building Intelligent Governments, Intelligent Cities, and the Intelligent Transportation system will be an essential part of that development and entering the stage of access to the 4.0 industrial revolution, building a smart city applying 4.0 technology to bring convenience, friendliness, and safety to people in each city. As a step ahead, the Transport industry gradually realizes its dream of developing intelligent transportation in developed cities like Hanoi and Ho Chi Minh City. The paper presents an overview of the impact of Industry 4.0 on key aspects of the transport sector in general and ITS development strategy in Vietnam. On that basis, state-of-the-art technologies - technology 4.0 are proposed to meet the demands of intelligent transportation development. The paper will show that 4.0 technology is the key to the development of ITS in Vietnam.
\end{abstract}

Keywords - development strategy; intelligent transport systems; industrial revolution 4.0; core orientation.

\section{INTRODUCTION}

Industrial Revolution 4.0 is having a profound impact on all aspects of social life. The impact of the revolution is such that no matter who you are, what you do, or even do not do, you are affected by it every day. At the center of the industrial revolution 4.0 is automation, labor-saving manufacturing, super-fast product speed, with consistent quality. Automation is a core issue so that we do not lag during this revolution. However, this concept has also fundamentally changed, not only the automation of industrial production [1]. Industrial revolution automation 4.0 is comprehensive automation with the powerful application of new technology. The new technology is in the form of robots, artificial intelligence, the Internet of Things, big data, and information technology. Besides, globalization of production has fundamentally changed the production of the world, strongly affecting all aspects of social life [2].

History has undergone three industrial revolutions. Transportation industry in each country has always played a key role in the view that traffic is the lifeblood of the country and always the first and important object that the industrial revolutions aim to. Industrial Revolution 1.0 with steam engines created mechanical means of transportation to replace rudimentary vehicles, fundamentally changed the revolution in terms of volume and distance of transport, forming railway lines, national and international shipping lines exist to this day. Industrial Revolution 2.0 has created high labor productivity, mass production has created cars, airplanes, high-speed trains, strong development in both quantity and quality, which has formed a series of highways, domestic and international routes [3]. Industrial Revolution 3.0 is an industrial revolution of robots and robots, making infrastructure and transportation more modern with automation applications, step by step towards intelligent traffic, from here, laying an important premise for today's 4.0 revolution [4].

Industrial Revolution 4.0 is the new technological achievements applied to production management processes, thereby creating labor productivity and increasing economic efficiency [5]. However, the consequences of the industrial revolution 4.0 on the transport sector may affect workers due to the loss of employment opportunities, with the advantage of cheap labor force, changing production methods (for example, Uber and Grab have upset the traditional taxi market). With Industry 4.0, the entire source of information is digitized and transparent, which will make it difficult to compete for small and medium-sized enterprises operating in the field of transport. For example, in the field of shipping, all businesses belong to the old generation of ships, outdated 
technology, large maintenance and maintenance costs [6]. On the other hand, the control system of maritime services requires a large amount of investment, human resources for deployment and operation must be qualified and knowledgeable in technology, these are no small challenges for regulators and businesses.

The 4th industrial revolution is having a profound impact on every country, every industry, field, business, and people. Therefore, the transport industry is not outside of this influence. Transport must "stay ahead" on industry 4.0 to turn opportunities for development and integration. This may be the first priority to get rid of the "stagnation" from Industry 1.0 with mechanical transport to Industry 2.0, which is the industrialization of vehicles, Industry 3.0 is automation with smart transport and up to Industry 4.0 is connectivity and sharing of intelligent transport modes [7].

Intelligent Transportation System (ITS) is the future direction of the transportation system. It is advanced information technology [8], data transmission technology, electronic sensor technology, control technology, and computer technology. It is leading to effectively integrate applications throughout a ground transportation management system established in a wide range, uphold the role of realtime, accurate, and efficient integrated transportation management system. ITS can effectively use existing vehicles, reduce traffic load and environmental pollution, to ensure traffic safety, improve transport efficiency, and thus to grow national attention [9].

There are many differences between conventional transport infrastructure and ITS; the first is that traditional infrastructure is a much easier-to-use technology, which, in theory, is always available in terms of design and testing. It has been around for decades, and there is an industry that is well-suited for supply and relevant capacity. On the other hand, ITS products and services are continually being updated and developed, so it has a shorter life span and is harder to describe and format, the market of suppliers and contractors is more limited and diverse [10]. When deciding to equip and use ITS applications, these differences must be considered because ITS devices are more related to differences that require more intellect and skills than manual work, and when put into operation together, ITS's subcontractors may find it difficult to access and manage the system. The development of this technology influenced by government or from the market itself has created change. The private sector will develop ITS technologies, which are expected to be marketed for products or services of this technology, such as the integrated use of telecommunications [11] and information technology embedded in vehicles, searching for facilities to improve service delivery efficiency, and expanding telecommunications markets. Often these developments can receive the best incentives from the government, such as securing access to telecommunications networks through regulation and providing access to national digital maps [12].

ITS is a combination of computing, information technology, and telecommunications - related to the transportation industry. Advanced ITS technologies are brought about by the mainstream development trends of these industries. ITS, therefore, can be defined as the application of computing, information, and communications technologies in the management of vehicles and networks related to the movement of people and goods in real-time. Therefore, technology plays a crucial role in the development of intelligent transportation. In the trend of Industry 4.0, taking advantage of 4.0 technologies to develop intelligent transportation is considered as a core solution to solving transportation problems in the orientation of modern infrastructure development in Vietnam.

Despite the industrial revolution, transportation still plays an essential and irreplaceable role; However, the 4.0 Industrial Revolution is a condition for the transport industry to make great leaps forward in both transportation mode and management model. In this article, the author presents some of the key challenges needed to meet the requirements of the transportation era 4.0. The authors not only analyzed the impact of Industry 4.0 on the transportation industry but also analyzed and proposed advanced technology solutions 4.0 to apply intelligent transport development in Vietnam.

\section{MATERIALS AND METHODS}

Industry 4.0 will take place in 3 main areas: Biotechnology, Digital, and Physics. In which, two fields will affect the transport industry: Digital and Physics, specifically as follows: The Digital field manifests itself in Artificial Intelligence (AI), the Internet of Things (IoT) and the Big Data (Internet of Things). The field of Physics includes Robots, 3D printing techniques, self-driving devices, new materials, and nanotechnology.

\section{A. Artificial intelligence (AI)}

There are many different definitions of artificial intelligence, but, understandably, artificial intelligence is a computer science [13]. It is built on a solid theoretical foundation. It can be applied in the automation of intelligent behaviors of computers, helping computers acquire human intellect such as know thinking and reasoning to solve problems, communicate by understanding language, speaking, learning, and adapting itself. Transport problems arise when the behavioral system is too difficult to model according to a predictable model due to being affected by things such as traffic, human error, or accidents [14]. In such cases, artificial intelligence can aid predictability. Currently, artificial intelligence is being used in transport in some areas, such as:

1) Driverless cars: Driverless cars are some of the most exciting new initiatives to become a reality in transportation. At that time, artificial intelligence played an important role in these driverless cars due to their ability to handle, control, and optimize. According to the statistics of Nils-Gerrit Wunsch, the number of self-driving cars registered globally from 2010 to 2019 increased sharply, especially Toyota's self-driving car market share [15]. The research results are clearly shown in Figure 1, in which, the number of statistical results of the growth of the number of self-driving cars of the world's nine largest car companies shows that AI has had a strong impact on the automotive industry in the next decade of the 21 st century.

2) Traffic management solution: Another way in which artificial intelligence technologies are used in transportation is in traffic management systems. Thanks to its processing, 
control, and optimization capabilities, artificial intelligence can be applied to traffic management and decision-making systems to enhance and streamline traffic management [16]. On the other hand, thanks to predictability, artificial intelligence also brings significant benefits to traffic management systems because they can recognize physical conditions, and the environment can lead to traffic congestion, from which they can automatically suggest alternate routes.

3) The application on the smartphone: There are now smartphone applications that assist users in traffic, such as real-time traffic updates provided by artificial intelligence through services such as Google Maps [17]. From the location data collected from a user's smartphone, these applications can predict and analyze traffic conditions in that area to better inform users' travel plans.

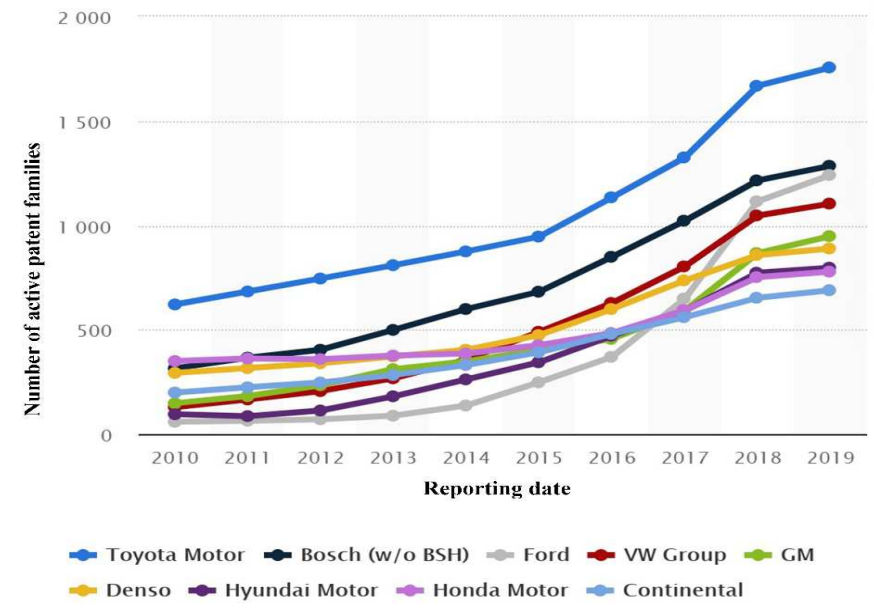

Fig. 1. The number of autonomous driving patents registered globally from 2010 to 2019 [15]

4) Penalize traffic violations: Artificial intelligence is currently being used in the ability to detect and punish people who violate traffic laws. This is often a challenge for the traffic police because it depends on the speed of each vehicle; the offender may be in or out of sight. However, with artificial intelligence, this is no longer a problem. By using advanced analytics and data processing capabilities, artificial intelligence can help detect and identify when drivers are drinking or over speeding so they can alert any traffic police in that area to stop them [18]. In summary, the use of artificial intelligence in transportation can bring significant benefits, such as improving safety issues in public transport, increasing the safety and efficiency of transportation [19]. Artificial intelligence can play a big role in developing and deploying new ways to deal with pollution and help scientists and engineers to find more environmentally friendly methods. However, there are also risks in the application of artificial intelligence in transportation as the self-driving car network system can be attacked, or millions of workers lose their jobs due to being replaced by machines.

\section{B. Internet of Things (IoT)}

Internet of Things (IoT) is becoming a part of everyday life in every industry, and around the world. IoT refers to a type of network that connects anything to the Internet-based on specified protocols through information sensors to conduct information exchange and communication to achieve intelligent recognition, positioning, tracking, monitoring, and administration. There are many different definitions of IoT, but according to Sutar et al. [19], we can understand IoT as follows: "IoT is the connection between people and people, between people and machines or things and between machines or things together via the Internet." IoT in transportation can help us track vehicles and people, connect infrastructure, and make transportation work better [20]. Some ways that IoT can change the transportation industry include:

1) Means of transport connected: Manufacturers already have connectivity systems that allow vehicle drivers to connect their smartphones and use various applications, navigate routes, listen to satellite radio, request roadside assistance, find open parking, remotely lock/unlock and watch online video [17].

2) The sensor car: Sensors have been used in vehicles, allowing them to perform some tasks. Some acceleration and braking sensations of cars help save fuel and reduce maintenance costs, some sensors, together with mobile applications, help diagnose engine problems and display travel logs. Cars can help drivers determine the amount of free space in a parking lot, give important warnings, collect data, and make accurate predictions for the weather. By connecting all sensors in the car to the IoT, vehicles can communicate with each other, collect data, and store data in cloud infrastructure, which will be used and further analyzed by businesses [21].

3) Infrastructure will be connected: The IoT will create connections between different vehicles, and between vehicles and transport infrastructure. The connected infrastructure will bring many benefits. If there is a traffic jam or accident on the route, the driver will be notified. By combining the transport infrastructure, IoT can create a collaborative system that can show how people reach their destinations safely and on time [22]. Figure 2 shows the traffic light system connected to the traffic camera, the gateway, and the wireless smart mesh IP sensor network of the vehicles to form an IoT-based traffic light management complex. That solution helps to adjust the time to change traffic signals very flexibly, avoiding traffic jams during rush hour.

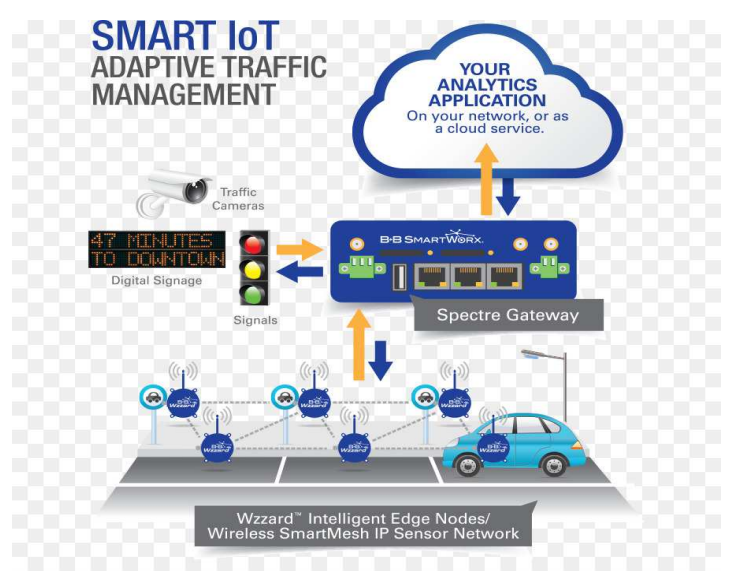

Fig. 2 Smart traffic light in adaptive traffic management [23] 


\section{Big Data}

According to Wikipedia, Big Data is a term for processing a huge and complex data set that traditional data processing applications cannot handle. Big Data is described by the following characteristics: Volume: The amount of data generated and stored. Variety: The types and types of data. Data is collected from many different sources, and data types also have many different structures [24]. Velocity: The speed at which data is generated and processed to meet needs and challenges on the path of growth and development. Veracity: The quality of the data obtained can vary greatly, affecting accurate analysis [25].

The use of Big Data in transportation brings significant benefits. Better data can help transportation managers understand the behavior of road users, provide information, and identify policy interventions. The biggest benefit of using Big Data can come from changing user behavior. For example, in Singapore, use real-time local traffic condition data to determine the price for tolls. This encourages drivers to avoid driving during the most congested times and to optimize the use of the road network. In addition, Big Data also affects many different aspects of the transport industry, such as asset management, transportation management, and especially logistics and supply chain management [26]. However, one issue that needs to be considered in using Big Data is the data security requirements or regulations.

\section{3D Printing Technology}

According to Lee et al., 3D printing technology (3D Printing - 3DP) is the process of creating physical models (real samples) from digitized models (3D design file on a computer) automatically via 3D printers. Unlike traditional design and manufacturing methods that can cause waste of materials, 3DP creates objects directly by cascading layers of materials in different ways depending on the technology used in 3D printing [27].

3DP is increasingly used in the field of transportation thanks to its advantages; for example, the world's first pedestrian bridge built with 3DP technology in Madrid, Spain, was put into use in May 2017. 3DP is and will affect both cargo and passenger transportation, both domestically and internationally. The following section gives some examples of the impact of 3DP on the transport industry.

1) For freight: 3DP can change supply chains by reducing factors such as manufacturing, assembly, distribution, warehousing, and retail sales to consumers [28], which helps streamline and minimize supply chain costs. Imagine a product before it reaches the consumer, going through a lot of stages such as shipping from production to foreign markets; after that, the goods are transported to domestic distribution centers, finally to the warehouse, retail centers, or consumers. Thanks to 3DP, a product can be printed on-site and delivered directly to customers. Thus high transportation costs, warehousing, long transit times, and significant carbon emissions are removed from the supply chain. Even for inland freight, the product can be printed directly at the customer's home.

2) For passenger transport: 3DP directly affects the transportation industry by changing the design and manufacturing of vehicles to suit the needs of passengers.
3DP is creating significant opportunities for the automobile manufacturing industry.

3) Reduce vehicle weight: Car manufacturers are always looking for new ways to reduce the burden of their products. A lighter car consumes less fuel, making it more environmentally friendly. To do so, they can optimize parts design by creating lighter structures thanks to innovative designs such as mesh, or reduce the number of vehicle parts thanks to the more appropriate design of the elements.

4) Reduce material loss: With 3DP, car manufacturers, layered parts, so they used only the amount of material needed to build their vehicle's components.

5) Create a custom car: Many car lovers like customizing their vehicles to get a unique car. It may be some exterior design features, but there are also some options for the vehicle's internal components. This unique requirement causes high production costs. With 3DP, creating just one version of a model is not a big deal.

6) Easy spare parts replacement: If some parts of a vehicle are broken, replacing them can be a real challenge, especially if it's an old one because the parts may no longer exist. By combining 3D scanning and additive manufacturing, manufacturers can recreate rare car parts.

In addition to passenger transport and freight transport, some other areas of the transportation industry affected by 3DP. It includes freight plan (reduced freight volume as replacement parts can be printed at the point of destination). It also includes the design and materials (innovation in the design of transport infrastructure and infrastructure at lower costs), management of transport organizations (forming mobile production facilities, reducing inventories, requiring other qualifications and skills).

\section{E. Experimental Setup}

The history of transport development is closely linked to the history of human development from the earliest beginnings when people used labor and animals as the primary means of transportation. Only when the industrial revolution broke out did the transport have significant changes, a strong impact on the socio-economic development of mankind. The history of transportation development under industrialization can be summarized as follows:

Transport in industrial license 1.0 (from the end of the 19 th century to the beginning of the 20th century) is the period of transport mechanization. Vessels and steam engine trains are used as primary transportation tools instead of humans and animals. Transport volume and transport distance, therefore, also increased [13]. Transportation in Industry 2.0 (from the early 20th century to 1960) was the era where the invention of electricity and mass production led to the introduction of high-quality aircraft and highspeed trains, thereby increasing the number of highways, domestic and international airports. Transport in Industry 4.0 (1960 - 2000) was the period of using electronics and information technology to automate production [14]. The manifestation of transportation in this period is the infrastructure and more modern means of transport with automation applications. Transport in Industry 4.0 (The year 
2000 to Present) is the latest development stage of transportation, mainly based on the development of the Internet of Things (IoT), gradually completing the smart transportation system [10].

\section{RESULTS AND DISCUSSION}

\section{A. Intelligent road Transportation}

In the field of road traffic, the 4.0 revolution is most evident through the advent of unmanned vehicles, which can "talk to each other" as well as intelligent transportation systems are gradually forming in some developed countries. The development in the field of computers, sensors, and cloud data allows unmanned cars from design ideas to "step out" of real-life [29]. With the sensor system and artificial intelligence, unmanned vehicles can recognize signal lights, strange objects, road maps to handle situations. People in the car can completely rest, work, entertain, and the story of taking you from point A to point B has a car. The generation of driverless cars promises to be many times higher because there will be no more drunk driving, red light, speeding, and reckless driving [30]. Currently, many car manufacturers such as GM, Nissan, Volkswagen, and some technology companies such as Waymo (from Google) are testing unmanned car technology in suburban areas and urban areas. Although at this time, the advanced level of autonomous driving does not allow the driver to surrender to the selfdriving car completely, this part of the car has many benefits [31]. Typically, in August 2016, an American man using a self-driving car from Tesla suddenly encountered symptoms of chest tightness. Thanks to the autopilot, he could contact his wife to tell the doctor to prepare, order the vehicle to move itself to the hospital and be given emergency aid promptly [32].

Accurate determination of vehicle traffic is essential. However, transportation projects are based on manually measured vehicle traffic survey numbers. Therefore, it is necessary to apply high technology to this to get accurate figures. Using artificial intelligence will not only count the traffic along with the traffic speed, but it will also give the traffic condition of the route, based on the colors displayed. People will know the vehicle density, traffic speed, congestion, or not and choose the most optimal itinerary. According to research by Hiroshi Makino et al. on using ITS technologies such as ETC2.0, CCRV camera, and VMS to develop and optimize the intelligent traffic system in a city in Japan to avoid traffic jams and traffic accidents. In this study, Figure 3 shows the safety and comfort level of drivers when traveling on highways with the interaction and support of the ETC2.0 RSU integrated autonomous driving system and CCTV camera [33].

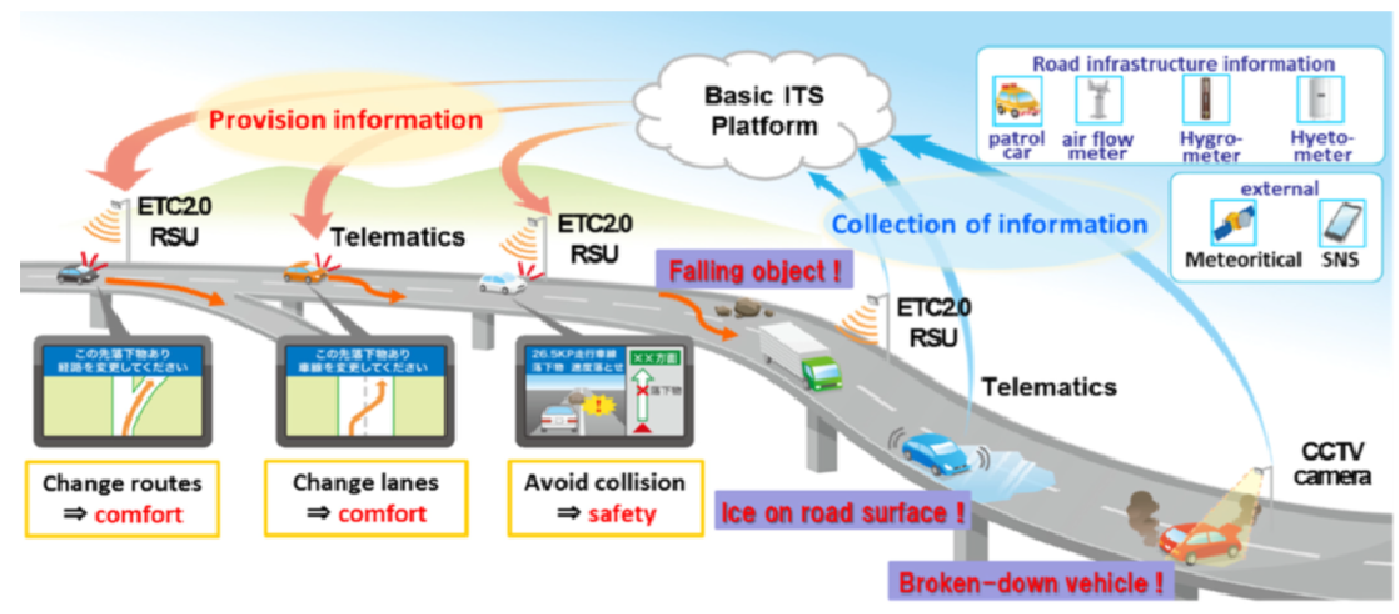

Fig 3 The safety and comfort level of drivers in support by the automated drive and ETC 2.0 [38]

The application of technology in traffic safety assurance is not only using conventional surveillance camera systems to monitor activities, traffic movements on the road but also the appearance of surveillance solutions and handling visual traffic violations on artificial intelligence (AI) platforms. With AI technology, it will detect, analyze, and warn against violations and detect drivers that may cause accidents. Drowsiness, drunkenness, weak health status, not wearing seat belts, carrying over the prescribed number of people, and giving timely warnings. This solution will support the maximum of traffic police in detecting driver violations, causing insecurity and danger to the lives of road users, taking photos, analyzing and recognizing license plates of the vehicles. Traffic violations common errors include overcoming a red light, speeding, going the wrong way, stopping at the wrong place, going in the opposite direction, discovering vehicles on the list of black license plates.
Immediately update the information of violation means to operate centers and patrol teams for timely handling and prevention of violations [34].

The AI application can improve the accuracy of license plate reading. With conventional solutions, not using smart chips, the accuracy in the license plate reading of the surveillance system is only about $90-95 \%$. Still, when using $\mathrm{AI}$, the identification number is $100 \%$, even in case the license plate is warped or out of focus". The AI application can identify the license plate, and the result will determine the process of the vehicle moving. Currently, the system of traffic monitoring and handling has been applied to 16 provinces and cities with intelligent identification, detection, traffic monitoring using AI technology has been raising the awareness of the driver of a vehicle [35].

Industrial Revolution 4.0 is bringing a significant change in the shipping business. "Car-hailing apps are constantly 
appearing. Enterprises, cooperatives transporting passengers and goods also gradually apply information technology in business management and administration". Big Data technology helps platforms to be smart when sharing, connecting and sharing data with state management agencies to facilitate traffic management [36]. As a result, in recent years, Vietnam's transport market has grown by 20$25 \% /$ year, especially in the field of ride-hailing by 30 $35 \% /$ year. According to statistics, if in 2017 , every day in Vietnam, about 500,000 trips are made by car-hailing companies, this number is 1 million by 2019. In the future, businesses need to put their business processes on software and applications to optimize management [37]. Companies with more significant economic potential can apply Big Data, in combination with smart cameras that store all user data, journey data, on-road data collection, behaviors of drivers, and customers, making traffic management safer and easier.

\section{B. Railway transportation}

For the Railway industry, through the 4.0 revolution, if the road has smart cars, the railway has unmanned trains, even trains without tracks. Not to mention the distant future, recently, China Railway Transport Company CRRC has launched a model of a train blending bus - tram-train called "smart bus." Thanks to sensor technology, computercontrolled, the $30 \mathrm{~m}$ long train does not run on conventional metal rails, but moves in white painted strips or also known with the new concept of "virtual rails." Sensors mounted under the streaks of paint, arranged along with the road and in the car to help the train follow the "tracks," and adapt to the surrounding environment, convenient handle unexpected situations in real-time [39]. The first smart train model has three cars with the capacity to carry 300 passengers and to carry 500 passengers in the future. Besides, thanks to digitization technology, passengers can buy tickets, change tickets remotely via phone or computer. This is what most major railway companies in the world are promoting [18].

According to a study by Lipika Deka and et al. about the Rail Transportation Cyber-Physical System, it shows that data on the route, the maximum train speed, the intersection, the density of vehicles and incidents on the tracks are displayed on display on board by using the European Train Control System. The train's parameters are also regularly updated to the system via GSM-R or radio system in ETCS, as shown in Figure 4.

\section{Trainguard solutions for ETCS Level 2}

GSM-R or other radio system (e.g. TETRA)

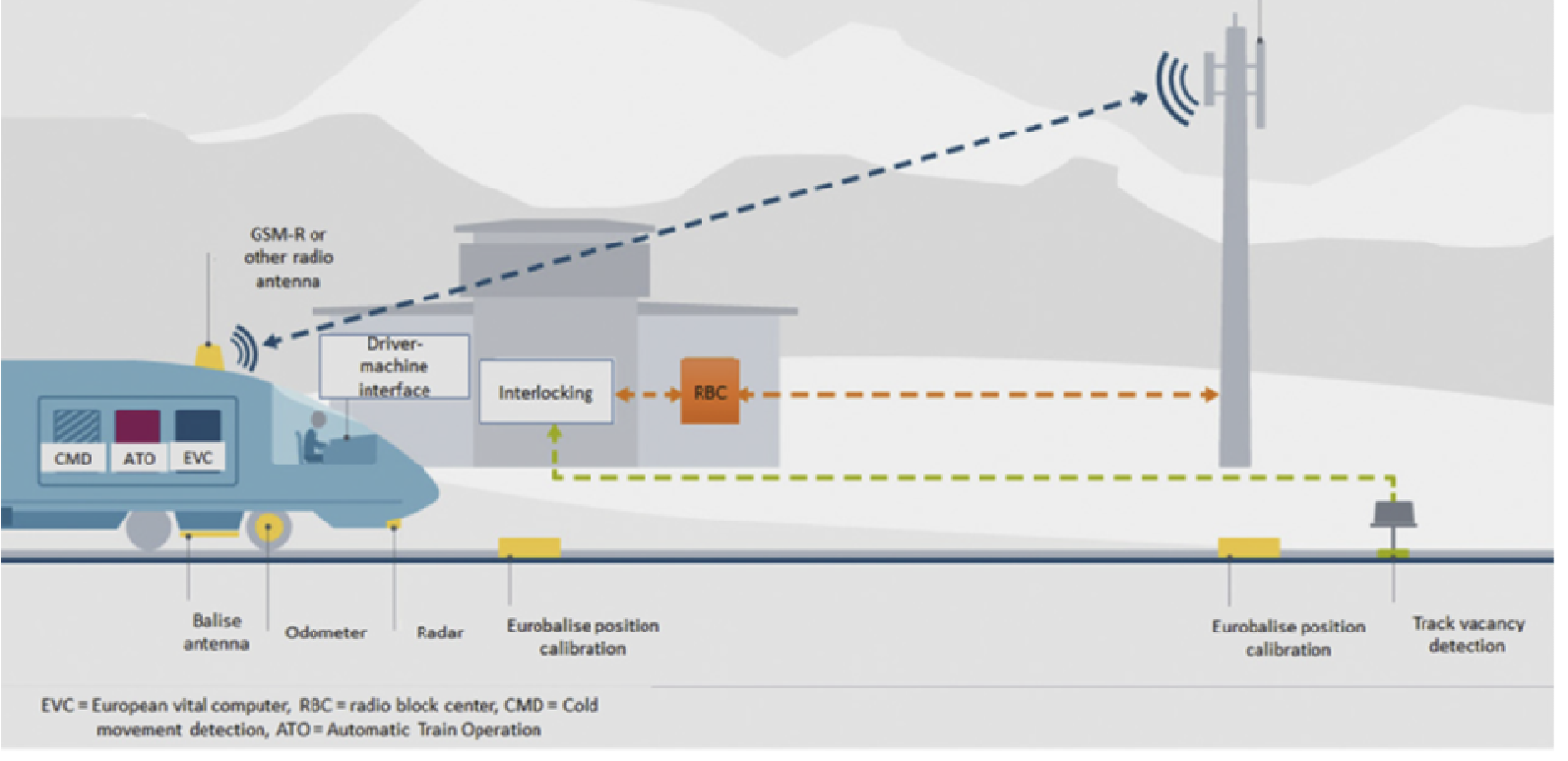

Fig. 4 Train guard solutions for ETCS level 2[39]

\section{Air Transportation}

In the field of aviation, passengers using this vehicle are now able to surf the net on the plane/at the airport, order according to their travel needs via smartphone/laptop. But all these utilities are only the first step when the 4.0 revolution reaches the aviation industry. In the future, with cloud sync data systems, aviation companies, tour operators have a considerable amount of customer data in their hands (preferred form of entertainment on the plane, popular destinations) [40]. These companies can track the traces that customers leave through clicks, swiping cards, or social media comments, thereby creating a unique set to identify potential customers in the virtual world.

With this amount of data, travel industry companies can understand and deliver products and services that meet the desired customer standards, as well as predict future customer needs. Currently, airlines, airports, tour operators are developing and operating independently [41]. However, in the future, with the technology of data integration and synchronization, these companies will soon cooperate, share data in real-time to boost profits, especially in the context of continually increasing customer traffic. Besides, through phone applications and cloud data storage systems, airlines, 
airports can "communicate" with customers in real-time. Passengers coming to the airport 4.0, can completely get information about the resort, restaurants, duty-free shops that customers may be interested in right at the airport. Currently, some airports in the world are aiming to produce and operate the airport system fully. Last July, Changi Airport (Singapore) began testing the fourth station of $100 \%$ automatic, allowing passengers to check-in and board. It also put to the test the most modern face recognition technology in the world [42].

Not only does it improve on services, like rail, road, and aviation are looking forward to future generations of drones. This scenario is entirely possible shortly when Boeing is planning to develop aircraft without pilots and is expected to conduct testing of this new technology in 2018. The new generation of aircraft can be integrated with flight control systems to determine the most suitable route based on the flight plan set by the pilot. At the same time, the computercontrolled system can operate the plane to take off, land, and fly.

In May and June 2017, Australia tested the world's first "contactless" customs technology at Cam Canberra International Airport. A passport-free facial recognition system verifies passengers by comparing their faces with data stored on the server. After this first test, Australian customs are expected to launch the second batch shortly. Biometric identification is not only applied for immigration, but it is also used to simplify the process of boarding. Sydney Airport has partnered with Qantas Airlines to use face data to shorten the departure process [43]. According to a new test, passengers who choose to fly Qantas can scan their faces and passports at a counter when they check-in. From there, they will not need to show their passports to
Qantas employees until they sit still on the plane. However, visitors still must go through the usual security checks to see if they have weapons or explosives. Always, all their transactions with Qantas are completely handled with face recognition [44].

\section{Sea transportation}

Not inferior to the above fields, the world maritime industry is cherishing many self-propelled ship designs, which is led by Norway with the design of a self-propelled freighter named Yarra Birkeland. The vessel has a capacity of 100 containers, began testing as planned at the end of 2018. Notably, Yara Birkeland is designed to be selfpropelled and dock using global positioning systems, radar, camera systems, and sensors. Its size is three times larger than a traditional container ship. Or Rolls-Royce engine manufacturing company, together with Advanced Automatic Waterway Application Company (AAWA) in Finland, is also working on a joint project to create remote control ship technology or fully automatic operation is expected to depart from the end of this decade [45]. In Asia, China Maritime Safety Administration and the Wuhan University of Technology are working together to implement the development project and researching multi-functional noncrew maritime vessels to find ways to develop unmanned ships for use in China's own military, commercial maritime industry [46]. Shipping experts believe that self-driving freighters may be popularly used for short distances. In the future, with long distances, traditional trains that used to need at least 25 people to operate may need fewer or completely without direct control if its route is not involved in natural disasters [47].

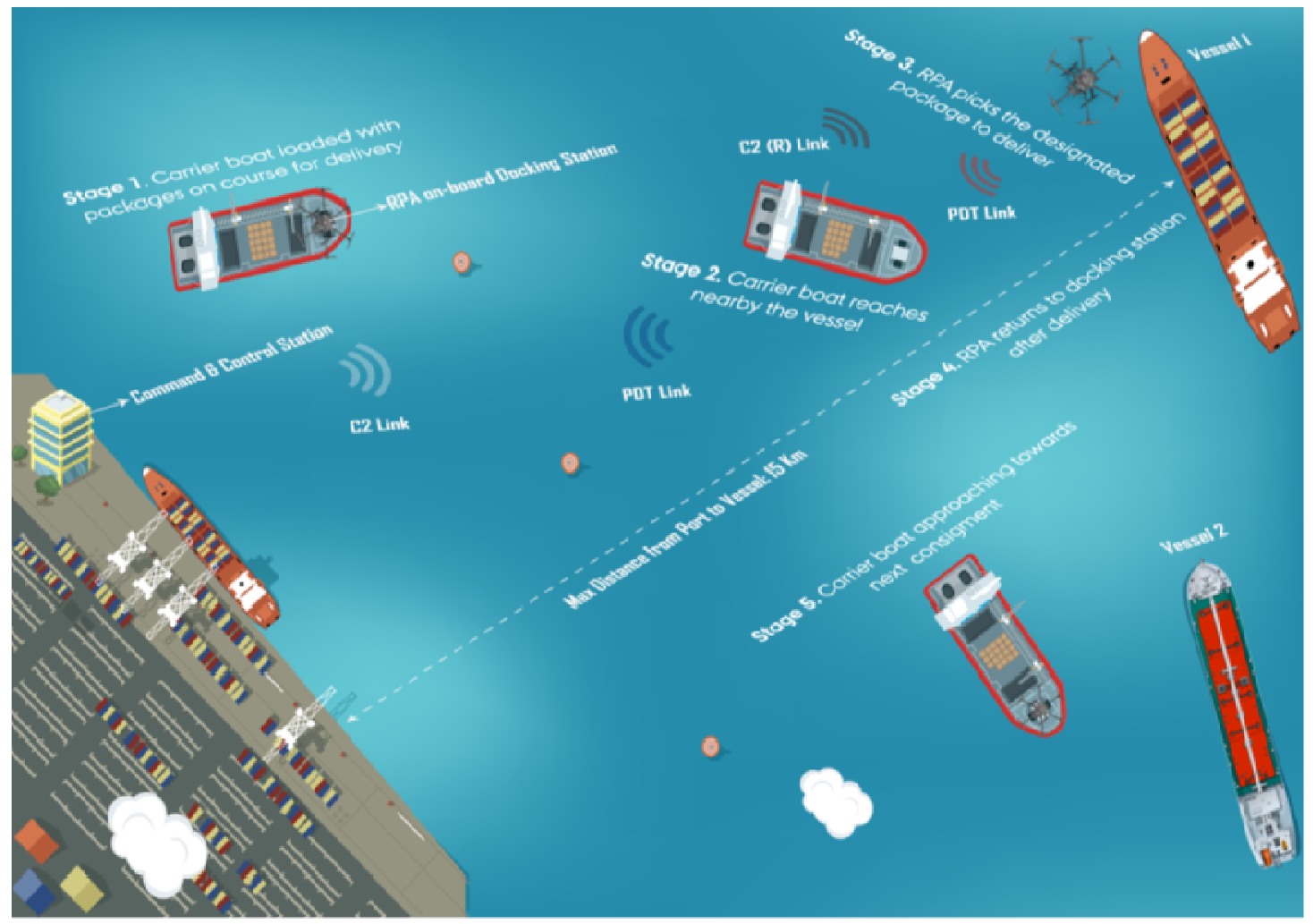

Fig. 5 The proposed system architecture for the automation of the end-to-end delivery process [48] 
In a study by Bilal Muhammad and colleagues presented a very practical solution to enhance port operations by the application of robotics and automation technology. In this study, the authors have built an optimal infrastructure structure using the Remotely-Piloted Aircraft System (RPAS), as shown in Figure 5 to improve cargo volume, reliability, and safety.

\section{CONCLUSION}

A fact can be realized that: Industry 4.04 .0 requires the transportation industry to make changes in both width and depth; Industry 4.0 could lead to a change in part or the whole of a country's transportation system. Vietnam's Transportation industry has shown signs of Industry 4.0 as the first step of forming a high-speed road system, applying information technology and the Internet in providing transport services. However, these manifestations are still at a local level, small and not systematic. The selection of appropriate solutions to make the transport industry become "smart" rather than an urgent requirement to contribute to creating "smart cities" in Vietnam.

Following the results of the digital revolution that has taken place for decades, along with computers and the Internet, there has been a fundamental change in the way people manufacture and control production and support decisions from digital space. With the Industrial Revolution 4.0 , the core foundation quickly spread to the fields of the transportation industry, from the perspective of state management to production, construction, from the field of roads, railways, waterways, maritime, aviation, registry.

4.0 technologies such as the Internet of Things, new materials, 3D printing, and Big Data will be the inevitable development trend, will be present in all areas of life. These technologies, when integrated into the construction of ITS infrastructure, will make significant breakthroughs in the future. However, besides the technical issues of ITS and IoT integration, the challenge in ITS implementation in Vietnam is organizational integration, completing the policy framework to coordinate the coordination activities among the concerned ministries and branches (the Ministry of Information and Communications, the Ministry of Transport and the Ministry of Public Security). When this problem is solved, it will be easy to build, manage, and operate a smart transportation system of a city, a region and beyond, the integration of systems for the whole country.

\section{REFERENCES}

[1] H. Makino, K. Tamada, K. Sakai, and S. Kamijo, "Solutions for urban traffic issues by ITS technologies," IATSS Res., vol. 42, no. 2, pp. 49-60, 2018.

[2] B. Muhammad, A. Kumar, E. Cianca, and P. Lindgren, "Improving Port Operations through the Application of Robotics and Automation within the Framework of Shipping 4.0," Int. Symp. Wirel. Pers. Multimed. Commun. WPMC, vol. 2018-Novem, pp. 387-392, 2018.

[3] A. Sładkowski and W. Pamuła, Intelligent transportation systemsproblems and perspectives, vol. 303. Springer, 2016.

[4] L. Li, X. Qu, J. Zhang, Y. Wang, and B. Ran, "Traffic speed prediction for intelligent transportation system based on a deep feature fusion model," J. Intell. Transp. Syst., vol. 23, no. 6, pp. 605616, Nov. 2019

[5] L. Deka, S. M. Khan, M. Chowdhury, and N. Ayres, Transportation Cyber-Physical System and its importance for future mobility. Elsevier Inc., 2018.
[6] M. Lom, O. Pribyl, and M. Svitek, "Industry 4.0 as a part of smart cities," in 2016 Smart Cities Symposium Prague (SCSP), 2016, pp. $1-6$.

[7] B. Chen, J. Wan, L. Shu, P. Li, M. Mukherjee, and B. Yin, "Smart factory of industry 4.0: Key technologies, application case, and challenges," IEEE Access, vol. 6, pp. 6505-6519, 2017.

[8] W. Yu and F. Zhao, "Prediction of critical properties of biodiesel fuels from FAMEs compositions using intelligent genetic algorithmbased back propagation neural network," Energy Sources, Part A Recover. Util. Environ. Eff., pp. 1-14, Jul. 2019.

[9] T. Zhang, W. Zhou, F. Meng, and Z. Li, "Efficiency Analysis and Improvement of an Intelligent Transportation System for the Application in Greenhouse," Electronics, vol. 8, no. 9, p. 946, 2019.

[10] D. Tokody, I. J. Mezei, and G. Schuster, "An overview of autonomous intelligent vehicle systems," in Vehicle and Automotive Engineering, Springer, 2017, pp. 287-307.

[11] C. Wang, X. Li, X. Zhou, A. Wang, and N. Nedjah, "Soft computing in big data intelligent transportation systems," Appl. Soft Comput., vol. 38, pp. 1099-1108, 2016.

[12] J. Schlingensiepen, F. Nemtanu, R. Mehmood, and L. McCluskey, "Autonomic transport management systems-enabler for smart cities, personalized medicine, participation and industry grid/industry 4.0," in Intelligent transportation systems-problems and perspectives, Springer, 2016, pp. 3-35.

[13] X. P. Nguyen and D. K. Pham Nguyen, "Experimental Research on the Impact of Anchor-Cable Tensions in Mooring Ship at Vung Tau Anchorage Area," Int. J. Adv. Sci. Eng. Inf. Technol., vol. 9, no. 6, pp. 1892-1899, 2019.

[14] R. Chaudhary, A. Jindal, G. S. Aujla, S. Aggarwal, N. Kumar, and K.-K. R. Choo, "BEST: Blockchain-based secure energy trading in SDN-enabled intelligent transportation system," Comput. Secur., vol. 85, pp. 288-299, 2019.

[15] S. He, A. Zhang, and M. Yan, "Voice and motion-based control system: Proof-of-concept implementation on robotics via internet-ofthings technologies," in ACMSE 2019 - Proceedings of the 2019 ACM Southeast Conference, 2019.

[16] S. Djahel, R. Doolan, G. M. Muntean, and J. Murphy, "A Communications-Oriented Perspective on Traffic Management Systems for Smart Cities: Challenges and Innovative Approaches," IEEE Commun. Surv. Tutorials, 2015.

[17] W. Ejaz, M. Naeem, A. Shahid, A. Anpalagan, and M. Jo, "Efficient Energy Management for the Internet of Things in Smart Cities," IEEE Commun. Mag., 2017.

[18] V. T. Pham, "Critical information for vietnamese economy aiming at a strategic breakthrough as approaching the industry 4.0," Int. J. Adv. Sci. Eng. Inf. Technol., vol. 9, no. 3, pp. 1008-1016, 2019.

[19] S. H. Sutar, R. Koul, and R. Suryavanshi, "Integration of Smart Phone and IOT for development of smart public transportation system," in 2016 International Conference on Internet of Things and Applications, IOTA 2016, 2016.

[20] C. T. Pham, K. H. Nhu, V. H. Dong, T. H. Le, and T. T. Hoang, "Development of PSO for tracking maximum power point of photovoltaic systems," Int. J. Adv. Sci. Eng. Inf. Technol., vol. 9, no. 5, pp. 1732-1738, 2019

[21] P. Molchanov, S. Gupta, K. Kim, and K. Pulli, "Multi-sensor system for driver's hand-gesture recognition," in 2015 11th IEEE International Conference and Workshops on Automatic Face and Gesture Recognition, FG 2015, 2015.

[22] A. R. Fayjie, S. Hossain, D. Oualid, and D. J. Lee, "Driverless Car: Autonomous Driving Using Deep Reinforcement Learning in Urban Environment," in 2018 15th International Conference on Ubiquitous Robots, UR 2018, 2018.

[23] G. Shahzad, H. Yang, A. W. Ahmad, and C. Lee, "Energy-Efficient Intelligent Street Lighting System Using Traffic-Adaptive Control," IEEE Sens. J., 2016.

[24] C. Yang, Q. Huang, Z. Li, K. Liu, and F. Hu, "Big Data and cloud computing: innovation opportunities and challenges," International Journal of Digital Earth. 2017.

[25] J. Stanley, D. Hensher, and M. A. Munizaga, "Big data and transport," in A Research Agenda for Transport Policy, 2019.

[26] T. Borgi, N. Zoghlami, and M. Abed, "Big data for transport and logistics: A review," in Proceedings of International Conference on Advanced Systems and Electric Technologies, IC_ASET 2017, 2017.

[27] J. Y. Lee, J. An, and C. K. Chua, "Fundamentals and applications of 3D printing for novel materials," Applied Materials Today. 2017. 
[28] L. C. Hwa, S. Rajoo, A. M. Noor, N. Ahmad, and M. B. Uday, "Recent advances in 3D printing of porous ceramics: A review," Current Opinion in Solid State and Materials Science. 2017.

[29] Y. R. V. S. Chandra, M. Shiva Harun, and T. Reshma, "Intelligent transport system," Int. J. Civ. Eng. Technol., 2017.

[30] D. González, J. Pérez, V. Milanés, and F. Nashashibi, "A Review of Motion Planning Techniques for Automated Vehicles," IEEE Trans. Intell. Transp. Syst., 2016.

[31] C. Chen, N. Tabssum, and H. P. Nguyen, "Study on Ancient Chu Town Urban Green Space Evolution and Ecological and Environmental Benefits," Nat. Environ. Pollut. Technol., vol. 18, no. 5, pp. 1733-1738, 2019 .

[32] A. Lei, H. Cruickshank, Y. Cao, P. Asuquo, C. P. A. Ogah, and Z. Sun, "Blockchain-Based Dynamic Key Management for Heterogeneous Intelligent Transportation Systems," IEEE Internet Things J., 2017.

[33] H. Zhu, K. V. Yuen, L. Mihaylova, and H. Leung, "Overview of Environment Perception for Intelligent Vehicles," IEEE Transactions on Intelligent Transportation Systems. 2017

[34] A. Balasubramaniam, A. Paul, W. H. Hong, H. C. Seo, and J. H. Kim, "Comparative analysis of intelligent transportation systems for sustainable environment in Smart Cities," Sustain., 2017.

[35] R. Abduljabbar, H. Dia, S. Liyanage, and S. A. Bagloee, "Applications of artificial intelligence in transport: An overview," Sustainability (Switzerland). 2019.

[36] N. H. Phuong, "What solutions should be applied to improve the efficiency in the management for port system in Ho Chi Minh City?," Int. J. Innov. Creat. Chang., vol. 5, no. 2, pp. 1747-1769, 2019.

[37] J. Mata et al., "Artificial intelligence (AI) methods in optical networks: A comprehensive survey," Optical Switching and Networking. 2018.

[38] E. Papa, M. te Brömmelstroet, C. Silva, and A. Hull, "Accessibility instruments for planning practice: A review of European experiences," Journal of Transport and Land Use. 2016.
[39] M. Kans, D. Galar, and A. Thaduri, "Maintenance 4.0 in railway transportation industry," in Proceedings of the 10th world congress on engineering asset management (WCEAM 2015), 2016, pp. 317331.

[40] A. Ai-Kaff, R. Alonso, M. Osman, and A. Hussein, "SkyOnyx: Autonomous UAV Research Platform for Air Transportation System (ATSys)," in IEEE Conference on Intelligent Transportation Systems, Proceedings, ITSC, 2018.

[41] J. H. Huh, "Plc-integrated sensing technology in mountain regions for drone landing sites: Focusing on software technology," Sensors (Switzerland), 2018

[42] T. Wang et al., "A framework for airfare price prediction: A machine learning approach," in Proceedings - 2019 IEEE 20th International Conference on Information Reuse and Integration for Data Science, IRI 2019, 2019.

[43] S. Teker, D. Teker, and A. Güner, "Financial Performance of Top 20 Airlines," Procedia - Soc. Behav. Sci., 2016.

[44] X. P. Nguyen, "The bus transportation issue and people satisfaction with public transport in Ho Chi Minh city," J. Mech. Eng. Res. Dev., 2019.

[45] Y. Zhao, B. Yan, W. Wang, Y. Lin, and J. Zhang, "On-Board Artificial Intelligence Based on Edge Computing in Optical Transport Networks," in 2019 Optical Fiber Communications Conference and Exhibition, OFC 2019 - Proceedings, 2019.

[46] S. Karthikeyan, "An environmental effect of Vitis vinifera biofuel blends in a marine engine," Energy Sources, Part A Recover. Util. Environ. Eff., vol. 38, no. 21, pp. 3262-3267, Nov. 2016.

[47] C. W. Armstrong, N. S. Foley, D. Slagstad, M. Chierici, I. Ellingsen, and M. Reigstad, "Valuing blue carbon changes in the Arctic ocean," Front. Mar. Sci., 2019.

[48] G. Zou, "Intelligent Design and Operation of Ship Energy Systems combining Big Data and AI," in 17th Conference on Computer and IT Applications in the Maritime Industries (Compit '18), 2018. 